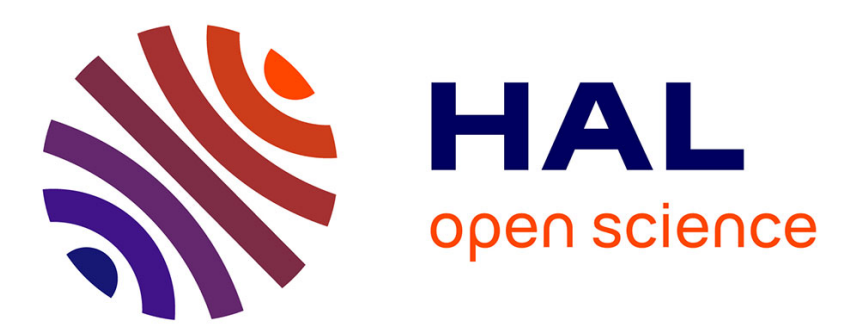

\title{
From Theory to Practice: Teaching Assistants' Role in Multi-campus Education
}

\author{
Abdullah Bahmani, Rune Hjelsvold
}

\section{To cite this version:}

Abdullah Bahmani, Rune Hjelsvold. From Theory to Practice: Teaching Assistants' Role in Multicampus Education. 18th Conference on e-Business, e-Services and e-Society (I3E), Sep 2019, Trondheim, Norway. pp.654-664, 10.1007/978-3-030-29374-1_53 . hal-02510130

\section{HAL Id: hal-02510130 \\ https://hal.inria.fr/hal-02510130}

Submitted on 17 Mar 2020

HAL is a multi-disciplinary open access archive for the deposit and dissemination of scientific research documents, whether they are published or not. The documents may come from teaching and research institutions in France or abroad, or from public or private research centers.
L'archive ouverte pluridisciplinaire HAL, est destinée au dépôt et à la diffusion de documents scientifiques de niveau recherche, publiés ou non, émanant des établissements d'enseignement et de recherche français ou étrangers, des laboratoires publics ou privés. 


\title{
From Theory to Practice: Teaching Assistants' Role in Multi-Campus Education
}

\author{
Abdullah Bahmani $^{1}$ (D), Rune Hjelsvold ${ }^{2}$ (B) \\ 1,2 The Norwegian University of Science and Technology (NTNU), Norway \\ 1,2 [Abdullah.Bahmani, Rune.Hjelsvold] entnu. no
}

\begin{abstract}
Teaching Assistants (TAs) are an indispensable part of higher education. TAs have two identities simultaneously: those of a student and of a teacher. However, the role of TAs' may not be clearly defined, resulting in a role ambiguity. In this study, we have researched the TAs' role in multi-campus education. Data for this research was collected through interviews with eight TAs at a Scandinavian multi-campus university who took a multi-campus TA role for the first time. This paper summarizes these TAs' work tasks in multi-campus courses. Their tasks included setting up technology, dealing with technical problems, and communicating with other TAs in the course. Our study suggests that TAs' challenges may be reduced if technical staff is caring for ICT equipment and technical problems, if direct interaction is provided between teacher and students, and if local teaching staff is involved in the activities at the remote campus.
\end{abstract}

Keywords: Teaching Assistant, Multi-campus Course, Activity Theory, Relevance Theory, Role Theory.

\section{Introduction}

TAs are an integral part of higher education. According to Webster, et al. [1], the role of TA in higher education is the result of a more extensive development of backup role in public welfare services like health, social and education. In higher education, it is more common for a course to be offered with the help of one or more TAs. For instance, in China, around $210 \mathrm{~K}$ people were working in Chinese universities as TAs in 2000 [2]. TAs are essential for higher education as they help the academic staff, and teach between one-third and half of the undergraduate courses ([3] as cited in [4]).

Despite the importance of the TAs' role in higher education, yet, there is no clearcut definition for the role of TAs [5, 6]. Some studies investigated the TA's role in higher education [7-10]. However, with the advent of multi-campus universities, our understanding of the TAs work and responsibility in multi-campus courses is remarkably limited. To address this gap, this study tries to examine the role of TAs at a Scandinavian multi-campus university who for the first time participated in multi-campus courses. As the number of multi-campus courses increase at the university level, new responsibilities arise. Our aim of doing this research is to identify the new responsibilities of the TAs in the multi-campus setting and to study potential impacts on the TAs' 
relationship with other actors, such as teachers and students. Also, we aim to address the challenges which arise from the differences between TAs' role in the single- and multi-campus settings. Therefore, the research questions that we explicitly are trying to address in this study are:

- RQ1. To what extent does the TA role in multi-campus courses differ from a singlecampus course TA role?

- RQ2. How can the challenges raised from these differences be addressed?

The significance of our contributions in this paper is threefold: First, it tries to differentiate the role of TAs in multi-campus courses from the single-campus setting. This is important, as there is little research considering the TA's role in multi-campus courses, and its differences from traditional courses. Second, it raises the reader's attention about the multi-campus TA role when assigning tasks other than what an actual TA has, as it may cause negative influence on the Student-TA-Teacher relationship. Third, it provides a theoretical and practical evaluation of the existing literature.

\section{$2 \quad$ Literature Review}

The TA role was introduced in the 1950s in the US [2]. According to Gilmore, et al. [11] it is for more than 50 years that TAs have taught up to half of the undergraduate courses. Edmond and Hayler [12] reported that the role of TAs was the result of an agreement in reducing the burden of the teachers. Raaper [13] defined TAs as postgraduate students who are hired by higher education institutions to teach part-time while. Often, a TA is also a doctoral student, and in some cases, a master's student. Edmond [14] believed that having a dual identity (student and teacher) in higher education makes it arduous to establish a "professional identity" for TAs. This can be a reason why there is an increase in the roles and responsibilities of the TAs [7-10, 15]. For example, Warhurst, et al. [9] reported that besides the increase in the number of TAs in Scotland, their roles are also expected to change significantly.

Having role ambiguity and increase in their responsibilities, TAs have some concerns and challenges in their student- and teacher-life. Cho, et al. [16] classified their concerns into class control, external evaluation, role, time, and communication. Gardner and Parrish [17] identified the following challenges that TAs are facing: Lack of preparation, difficulties in balancing the time for research and teaching, lack of pedagogical knowledge, and reliance on previous class experience. Lueddeke [18] warned about assigning TAs in the classroom without proper preparation and training. The literature frequently recommends TA training, preparation, and pre-hiring assessment, but there is currently no rigorous program to do so. According to Smith and Smith [19], it is needed to recruit TAs through a process similar to the one for new academic staff, as currently TAs are chosen from students by a faculty member.

In the literature, researchers consider two kinds of relationship for the TAs: TAstudents and TA-teacher. The abovementioned challenges and concerns for the TAs may result in an inefficient interaction between TA and students affecting the students' learning quality and their perception. Equally important, a poor experience in teaching, 
may hurt the development of the TAs' teaching skill, satisfaction, and motivation and may result in the TA losing the interest in pursuing an academic position [20]

While Smith and Smith [19] studied the change of the TA role in an online course, there is little research on the multi-campus TA role. In this study, we will try to explore the TA role with the help of activity theory [21], analyses their role by the relevance theory and the role theory. Moreover, we will summarize their expectations with some recommendation in the conclusion section.

\section{Theoretical Framework}

In this study, in order to identify the role of TAs and their responsibilities in a multicampus course, we adopted the activity theory [21], in particular, the activity system [22] as it is shown in Fig. 1. It provides a holistic view of a "real-world condition."

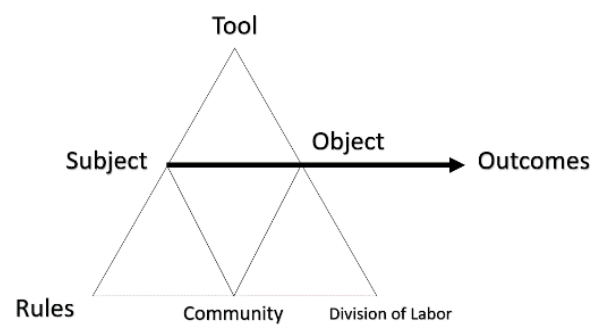

Fig. 1. Activity System

Based on the Activity System, an external force changing one or some elements of the system, may result in contradictions (e.g., incompatible evaluations, restrictions, disagreement, etc.) within and between the elements. TAs, as a part of the community in the activity system, help the teacher and students in the teaching and learning process. Extending a single campus course to the multi-campus setting brings some new responsibilities and consequently challenges to TAs as discussed later in this paper.

To identify the relevance of the tasks assigned to the TAs in our case, we used the relevance theory. As shown in Fig. 2, Gorayska and Lindsay [23], defined the relevance as follows:

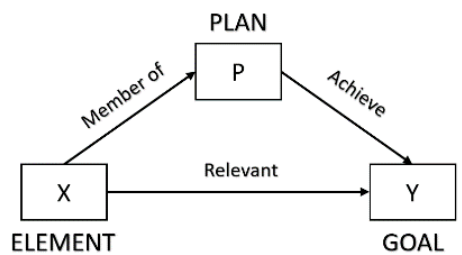

Fig. 2. Definition of Relevance adopted from Gorayska and Lindsay [23] 
" $X$ is relevant to $Y$ if $Y$ is a GOAL and $X$ is an ELEMENT of some PLAN which is sufficient to achieve that GOAL." Therefore, "X is irrelevant to $Y$ if $Y$ is a GOAL and $X$ is NOT an ELEMENT of any PLAN which is sufficient to achieve that GOAL."

Wilks [24] involved an AGENT to the definition of relevance: "SOMETHING is relevant to SOMEONE (who seeks to achieve some GOAL). Therefore, the definition of relevance in the presence of an agent is shown in Fig. 3.

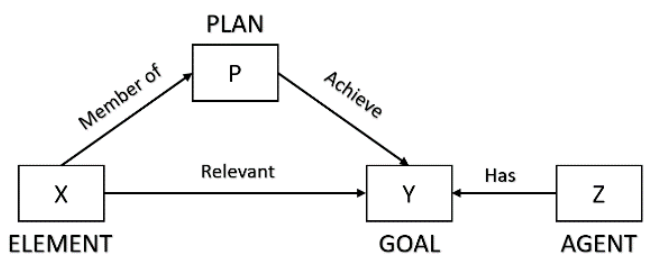

Fig. 3. Definition of Relevance with the presence of an Agent adopted from Gorayska and Lindsay [23]

According to Gorayska and Lindsay [23], goal is known motivation, which includes "aims, objectives, wishes, desire, interests, intentions, and wants.". Goals are reachable by an array of known actions. These actions include "methods, strategies, and procedures," which altogether shape the plans. Plans contain elements, which are "operations, actions, and related necessities" to achieve the goals. Each element is acquired from the knowledge source to support practical actions.

Moreover, we also used the role theory to analyze the process of taking a role theory and the result of assigning different tasks to TAs. Rizzo, et al. [25]defined the organizational role as " $a$ position within an organizational structure that comes with a specified set of tasks or responsibilities." Therefore, a person who is assigned to a role is expected to do a specific set of tasks related to that role [26]. However, managers or employers do not often specify the roles accurately [27] resulting in reducing or expanding the activities related to the roles and consequently to role conflict and role ambiguity [28]. Role conflict means the role owner is asked to perform some tasks, which is inconsistent or incompatible with each other. Role ambiguity rises when there are no clear borders for the role, which means that the role owner does not know which tasks, are related to his or her role. Role conflict, in turn, leads to role strain [29]. It means that the role owner has difficulty in fulfilling the given role. Moreover, according to Van Maanen and Schein [30], people must negotiate on the role while they are taking a role. According to Deutsch [31], negotiating on a role can happen when both parties have the same power to persuade their ambitions to reach their goals.

Based on the abovementioned theories and definitions, when somebody has a role, he or she has a goal to achieve. Also, there are some elements and requirements which are already planned to lead this person to his or her goal. So, an element is relevant to a goal, if it is a member of the "plan" and it helps to achieve the goal. Hence, in our case, AGENT is a person with a TA role whose GOAL is helping the teacher and students in the education process, as well as acquiring experience in teaching as a future 
teacher. The role of a TA is planned to consist of those elements (as their tasks) and related prerequisites, which help them to reach their GOAL.

In this study, to address the research questions, we used this theoretical framework to analyze our data.

\section{$4 \quad$ Research Methodology}

Recently, a Scandinavian university has been merged with several state colleges to become a multi-campus university. Leaders of the university, as Groenwald [32] already discussed, have been facing a challenge related to quality assurance. They have been trying to find a solution, which provides equal access to resources such as courses and curricula with the same quality for students at different campuses. To address this challenge, so far, there have been some initiatives to extend existing courses from a singlecampus style to a multi-campus setting to extend the course offering to students at other campuses [33]. The technical solution was nearly the same in all cases, based on unidirectional video streaming of lectures held by a single teacher at the main campus to students gathered in a classroom at the other campus. For each of these courses, one or two TAs were recruited at each campus to setting up and monitoring the video stream and help the teachers and students as well.

In this study, in order to reach our aim, we had a semi-structured interview with eight TAs (four doctoral students and four master's students) who assisted in multi-campus courses, in Fall 2018. As there had not been so many multi-campus courses at the university level before, these TAs were among the first ones to act as multi-campus TAs. The participants had already been involved in single-campus courses, and they were familiar with the related responsibilities. Questions asked to the TAs only addressed the new responsibilities in the multi-campus setting. We did not ask any question about the single-campus TA role for comparing as it was already known by the literature, and participants had already had experience in a single-campus setting. Interviews were done either in-person at each campus or through Skype meetings. The interviews varied in length from 20 to 30 minutes. The recorded files were then transcribed and qualitative data analyzed with Nvivo 12 . We used activity theory to specify the role of TAs and their relationships with other stakeholders in the context of a multi-campus course. The relevance theory helped us to examine the relevance of the new responsibilities with the actual role of a TA in a multi-campus setting. The role theory also helped us to analyze the challenges posed by the new responsibilities and specify TAs expectations to fulfill the differences between two different course settings.

\section{$5 \quad$ Findings}

Concerning the activity theory for single-campus courses, a TA can be considered a part of the community element and thereby will be having a direct relationship to the teacher as subject and students as object and the related responsibilities defined based on these relationships. The TA helps teacher and students in the teaching and learning process, as shown in Fig. 1. 


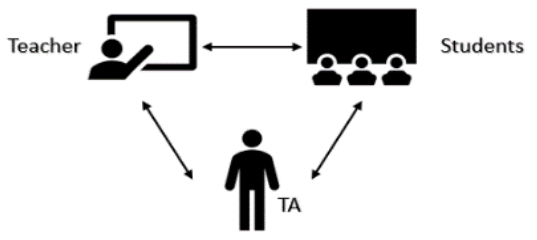

Fig. 4. TAs' relationships in single-campus courses

In our multi-campus setting, as shown in Fig. 5, the TAs had more complex relationships with other elements. Therefore, they were assigned some new and additional tasks. These tasks were related to setting up technology, dealing with technical failure, and communicating with other TA(s) to exchange the status of the link between campuses and to relay remote campus students' question to the teacher at the main campus.

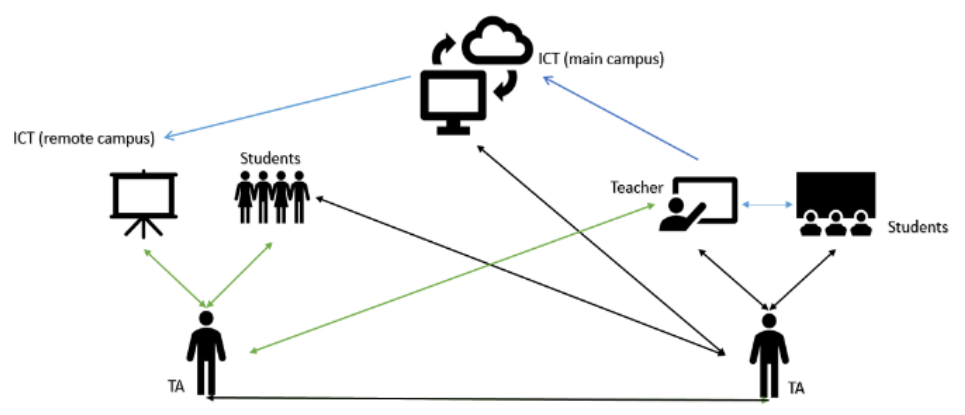

Fig. 5. TAs' relations in multi-campus courses

Participants in our study took the TA role in two different ways. Those who were master's student assigned to the TA role by the administration after sending the application form, while the teachers assigned doctoral students to the role as a part of their duty work. As an organizational role, the tasks of TAs were not clearly identified. Also, none of the TAs received any formal training and preparation for the role of TA in the multi-campus course. Before and after taking the TA role, they did not negotiate over the assigned tasks:

[TA] "I got sort off thrown into it from the start." "I was not really informed about that. I got to learn that after I was chosen for the position."

TAs identified that their role was not a practical role:

[TA] "It was more of an administrative job, not so much of a teaching job. I did not help the students with understanding the course."

[TA] "my entire duty was into the administration to look into administration kind of work." 
The main reason for having such a role is that they were mostly busy with irrelevant tasks such as followings:

Technology Setup. In our multi-campus setting, in order to share the lecture from the main campus to the remote one, TAs had to show up in the lecture room 10-15 minutes before the sessions, to set up the technology devices, make sure the link between the campus was stablished, and the audio and video were being transferred between the campuses seamlessly.

[TA] "I had to come in a reasonable time [15-20 minutes earlier] to make sure that everything was set up and running."

Deal with Technical Problems. During the lectures, TAs had to keep an eye on the technical equipment connecting the campuses:

1. To deal with minor technical problems and provide the necessary equipment.

[TA] "I will be in the class whole time, in case there are some problems with the transmission." "That would be more on the technical level. Make sure that everything works. Making sure that there are no technical issues. Also providing the necessary equipment on all campuses to make sure that this works

2. To contact technical support staff to inform the technical problems to come and solve:

[TA] "Make sure that there are people available if something happens, which was the problem we had." "When we had technical issues with the streams not starting, the hard part was to make technical contact with their maintenance unit up in [main campus]."

Communicate with Other TA(s). TAs on the same course but at different campuses had to have constant communication with each other:

1. To exchange the link status and technical problems.

[TA] "It was more communication if there was something wrong with the stream ...; the automatic tracking camera is not always turned correctly. That kind of stuff."

2. To relay the remote students' questions to the teacher on the main campus.

[TA] "When students had questions to me, then I had to make sure that the questions were sent up to [main campus] TA and to the lecturer (or guest lecturer) and make sure that they got the answer.

The tasks mentioned above are crucial for a successful outcome of multi-campus teaching. The responsibility to handle these tasks was not assigned to anybody else. 
Therefore, assigned to these tasks, TAs had to give them higher priority than other tasks. This created a role conflict for the TAs. It was difficult for them to balance their tasks. Consequently, they did not have as much time to interact with students as they were expecting.

[TA] "you spend a lot more time coordinating and just making sure that pure technical aspects of the course are working, like the live stream, rather than actually interacting with the students and having that one-to-one interaction."

These tasks made the TA role challenging for our participants. All of them indicated that if they had a choice, they would not choose a multi-campus TA role. As a potential improvement, they suggested that hired TAs were properly introduced to the particularities of the multi-campus TA role before recruiting, and that a training and preparation assistance was offered before the semester. In addition, they asked for the presence of technical staff who can care for the technology and who can handle technologyrelated difficulties. TAs having a local teaching staff in a remote campus preferred not to spend time on communication with other TA in the course for remote students' questions. They also expected the university to install technology that would provide a multi-directional link between campuses, which does not need for TAs' communication.

\section{Discussion}

Our findings show that there were no changes to the TA recruitment process, but there are new and challenging responsibilities assigned to them. TAs, who were doctoral students, were assigned to the courses as a part of their duty work. Master's students were selected by a faculty member as mentioned by Smith and Smith [19], which is common in TAs hiring. None of the TAs were offered any training for the new tasks and responsibilities and were operating based on their knowledge and experience, which is in agreement with the work of Lueddeke [18].

In this study, the process of the TAs role taking caused some friction between the TA and the university. Firstly, because the role responsibilities were not clearly communicated to the TAs when they were hired (role ambiguity). Secondly, because during the semester, TAs were assigned to different types of tasks that, each required a specific level of time and effort (role conflict). Finally, because the TAs had no means for renegotiating the TA terms once they were hired (role-taking).

There are similarities between the role of TAs in this study, and those described by Smith and Smith [19], as TAs were mostly busy with non-teaching tasks like dealing with logistics and technology. For example, technology setup and dealing with technical failure are time-consuming and demanding tasks for multi-campus TAs. They could solve some minor problems, but the complex ones were too demanding, knowledge wise, and time wise (role strain). To solve these role conflicts, TAs suggested the presence of technical staff or a facilitator who has just responsibilities other than TAs'. 
TAs in main and remote campuses also had to have constant communication to exchange the status of the link between campuses. So, they had to spend much of their time on monitoring technology to make sure the audio and video streamed smoothly between campuses. Relaying the remote students' question to the teacher was another task that TAs were given. Remote campus TAs had to spend time to make sure that the question was transferred to the teacher via the TA in the main campus. To solve this problem, there is a need for a multi-directional link between campus that remote students can have direct interaction with a teacher in the main campus. Also, the presence of a local teaching staff who can help remote students is another solution. These tasks are not related to ordinary TAs' role. First, these tasks were not already planned for the role, and there were not the required prerequisites like training and preparation. Second, the mentioned tasks were not on the list of tasks that lead a TA to achieve his or her goal: helping the teacher and students in the education process and prepare for future as a would-be teacher.

Our findings show that having a role in the education process, like a teacher, and a role related to other tasks such as logistics and technology brings role conflict to TAs. It was difficult for doctoral students to make a balance in terms of time and effort between their research and different assigned tasks as TA (role strain). This finding is in line with Gardner and Parrish [17]. Also, our finding supports the work of Lowman and Andreoli Mathie [20], as TAs were busy with non-teaching tasks, they could not establish a productive relationship with the students to help them in their learning process. TAs' tasks in multi-campus courses hindered them from having excellent practical experience in teaching as a would-be teacher.

\subsection{Implication for theory}

The theoretical contribution of this paper is giving an account to the activity theory in identifying a role and its relationships in the context. Also, in this paper, the combination of the relevance and role theory helped us to find the relevance of the tasks to a role.

\subsection{Implication for practice}

Multi-campus universities can use our findings if they want to assign TAs for multicampus courses. Our findings can help them not to assign the tasks which are not relevant to a TA role and prevent the possible negative impacts or at least provide some training and preparation steps to make them ready for the new style of TA role.

\subsection{Limitations of the research}

Our research has a limitation in terms of scale, as we covered courses share between two campuses. However, we believe that in the case of more campuses, some parts of our findings can be generalized. Also, this research has a limitation in the size of the participants, as there were just eight TAs who took the multi-campus TA role. 


\section{Conclusion}

In this study, we showed that as the role of TAs is not well-defined, TAs may be assigned a variety of tasks that are not handled by others. Several new tasks needed to be taken care of to ensure successful multi-campus courses, including administrative and technical support tasks. These tasks included setting up technology, dealing with technical problems, and communicating with other TAs in the course. It may seem easier for a multi-campus university to assign such unrelated tasks to TAs rather than having to add them to the administrative and technical support staff. As demonstrated in the cases studied in this paper, such an approach puts a heavy burden on the TAs. This extra burden can impair the Students-TA-Teacher relationship and thereby have a negative impact on the teaching and learning outcome.

To overcome these challenges, universities should provide some other roles in the classroom, letting the TAs maintain their traditional roles - i.e., supporting the local students in their learning. Alternatively, the universities should offer a training or preparation step to allow them to become familiar with the new role and let them make a choice. Finally, universities can install technology, which support a multi-directional connection between the campuses that students can have direct interaction with the teacher on the other campus to reduce the extra burden on the TAs.

\section{References}

[1] R. Webster, P. Blatchford, P. Bassett, P. Brown, C. Martin, and A. J. E. j. o. s. n. e. Russell, "Double standards and first principles: Framing teaching assistant support for pupils with special educational needs," vol. 25, no. 4, pp. 319-336, 2010.

[2] C. Lal Chandrakar and Y. Bentao, "From learning theory to academic organisation: The institutionalisation of higher education teaching assistant position in China," International Journal of Higher Education, vol. 7, no. 3, pp. 124-134, 2018.

[3] S. Ericksen, "Teaching Fellows, Memo to the Faculty 13 (Ann Arbor, Centre for Research on Learning and Teaching, University of Michigan)." 1965.

[4] L. Crewe, "Arena symposium: teaching assistants: Graduate teaching assistant programmes: the challenge ahead," Journal of Geography in Higher Education, vol. 20, no. 1, pp. 83-89, 1996.

[5] T. Kerry, "Towards a typology for conceptualizing the roles of teaching assistants," Educational Review, vol. 57, no. 3, pp. 373-384, 2005.

[6] P. H. Smith, "The paradox of higher vocational education: the teaching assistant game, the pursuit of capital and the self," Educational Review, vol. 70, no. 2, pp. 188-207, 2018.

[7] S. Graves, "New roles, old stereotypes-developing a school workforce in English schools," School Leadership \& Management, vol. 34, no. 3, pp. 255-268, 2014.

[8] R. Webster, A. Russell, and P. Blatchford, Reassessing the impact of teaching assistants: How research challenges practice and policy. Routledge, 2012.

[9] C. Warhurst, D. Nickson, J. Commander, and K. J. B. E. R. J. Gilbert, "'Role stretch': assessing the blurring of teaching and non-teaching in the classroom assistant role in Scotland," vol. 40, no. 1, pp. 170-186, 2014. 
[10] S. Tucker, "Perceptions and reflections on the role of the teaching assistant in the classroom environment," Pastoral Care in Education, vol. 27, no. 4, pp. 291-300, 2009.

[11] J. Gilmore, M. A. Maher, D. F. Feldon, and B. Timmerman, "Exploration of factors related to the development of science, technology, engineering, and mathematics graduate teaching assistants' teaching orientations," Studies in Higher Education, vol. 39, no. 10, pp. 19101928, 2014.

[12] N. Edmond and M. Hayler, "On either side of the teacher: perspectives on professionalism in education," Journal of Education for Teaching, vol. 39, no. 2, pp. 209-221, 2013.

[13] R. Raaper, "'Peacekeepers' and 'machine factories': tracing Graduate Teaching Assistant subjectivity in a neoliberalised university," British Journal of Sociology of Education, vol. 39, no. 4, pp. 421-435, 2018.

[14] N. Edmond, "The role of he in professional development: Some reflections on a foundation degree for teaching assistants," Teaching in Higher Education, vol. 15, no. 3, pp. 311-322, 2010.

[15] S. Minondo, L. H. Meyer, and J. F. Xin, "The role and responsibilities of teaching assistants in inclusive education: What's appropriate?," Journal of the Association for persons with Severe Handicaps, vol. 26, no. 2, pp. 114-119, 2001.

[16] Y. Cho, M. Kim, M. D. Svinicki, and M. L. Decker, "Exploring teaching concerns and characteristics of graduate teaching assistants," Teaching in Higher Education, vol. 16, no. 3, pp. 267-279, 2011.

[17] G. E. Gardner and J. Parrish, "Biology graduate teaching assistants as novice educators: Are there similarities in teaching ability and practice beliefs between teaching assistants and K-12 teachers?," Biochemistry and Molecular Biology Education, vol. 47, no. 1, pp. 51-57, 2019.

[18] G. R. Lueddeke, "Training postgraduates for teaching: Considerations for programme planning and development," Teaching in Higher Education, vol. 2, no. 2, pp. 141-151, 1997.

[19] K. Smith and C. Smith, "Non-Career Teachers in the Design Studio: Economics, Pedagogy and Teacher Development," International Journal of Art and Design Education, vol. 31, no. 1, pp. 90-104, 2012..

[20] J. Lowman and V. Andreoli Mathie, "What should graduate teaching assistants know about teaching?," Teaching of Psychology, vol. 20, no. 2, pp. 84-88, 1993.

[21] L. S. Vygotsky, Mind in society: The development of higher psychological processes. Harvard university press, 1980.

[22] Y. Engeström, R. Miettinen, and R.-L. Punamäki, Perspectives on activity theory. Cambridge university press, 1999.

[23] B. Gorayska and R. Lindsay, "The roots of relevance," Journal of Pragmatics, vol. 19, no. 4, pp. 301-323, 1993.

[24] Y. Wilks, "Relevance must be to someone," Behavioral and Brain Sciences, vol. 10, no. 4, pp. 735-736, 1987.

[25] J. R. Rizzo, R. J. House, and S. I. Lirtzman, "Role conflict and ambiguity in complex organizations," Administrative science quarterly, pp. 150-163, 1970.

[26] D. L. Rogers and J. Molnar, "Organizational antecedents of role conflict and ambiguity in top-level administrators," Administrative Science Quarterly, vol. 21, no. 4, 1976.

[27] R. L. Kahn, D. M. Wolfe, R. P. Quinn, J. D. Snoek, and R. A. Rosenthal, "Organizational stress: Studies in role conflict and ambiguity," 1964. 
[28] J. J. Ebbers and N. M. Wijnberg, "Betwixt and between: Role conflict, role ambiguity and role definition in project-based dual-leadership structures," human relations, vol. 70, no. 11, pp. 1342-1365, 2017.

[29] W. J. Goode, "A theory of role strain," American sociological review, pp. 483-496, 1960.

[30] J. E. Van Maanen and E. H. Schein, "Toward a theory of organizational socialization," 1977.

[31] M. Deutsch, The resolution of conflict: Constructive and destructive processes. Yale University Press, 1977.

[32] S. L. Groenwald, "The challenges and opportunities in leading a multi-campus university," Journal of Professional Nursing, vol. 34, no. 2, pp. 134-141, 2018.

[33] R. Hjelsvold and A. Bahmani, "Challenges in Repurposing Single-Campus Courses to Multi-Campus Settings," Laring om laring, vol. 3, no. 1, 2019. 